Behavioral dengan Teknik Desensitisas Sistematis untuk Mereduksi Kecemasa Menghadapi Ujian, Studi Eksperimen Pada Siswa Kelas X SMA Negeri 2 Singaraja. Tesis. Singaraja: Uni Penerbitan IKIP Negeri Singaraja.

Turmudhi, Audith. 2004. Kecemasan Menghadapi Ujian Sekolah. Jakarta: PT. Raja Grafindo Persada.

Uyanto, Stanislaus. 2009. Pedoman Analisi Data dengan SPSS. Yogyakarta: Grah Ilmu.

Widowati, Asri. 2010. Pengaruh Mind Map Terhadap Kemampuan Kognitif dan Kreativitas Siswa dalam Pembelajaran Sains Meaningfully. Jurnal Pendidikan Universitas Negeri Yogyakarta. Th X. Vol. 10 No. 2.

Yovan. 2008. Sekilas Mengenai Mind Map. Jakarta: Gramedia.

\section{PELATIHAN MEMBACA AL-QUR'AN UNTUK MENURUNKAN TINGKAT STRES PADA PENDERITA DIABETES MELLITUS \\ TIPE DUA PEMULA}

\section{Nur Habibah}

Dosen Fakultas Psikologi Universitas Muhammadiyah Sidoarjo. Telp. : 08983397772

\section{ABSTRACT}

This research was to know the effectiveness of reading tartil Al-Qur'an training according to waqaf and washal with deep breathing to decrease stres for diabetics sufferer. The condition of the subjects were being stable so they could accept their desease, and after that they could adapt to the desease. This research was quasi experimental involved six diabetics sufferer. The characteristic of subject was: Moslem, able to read tartil Al-Qur'an, age $35-55$ years old, average social economic level, suffer diabetes minimal for 2 years, got stres score scale average until high, prepare as voluntary of the research, and no consume medicine. This training were given along three weeks and the materials were: diabetes mellitus, stres, reading Al-Qur'an with deep breathing, and done in five times confluence. Data of stres scale collected were analyzed by visual inspection, that were the stres level of the subjects compared between the measurement before and after the treatment, there were differences the stres level of subject before and after the treatment reading Al-Qur'an, for subject 3 and subject 5 . Subject 1 and subject 4 the decreased were just little. Subject 2 and subject 6 experienced decrease stres scale score in medium. The decrease were not change the category the subject in medium level. Subject 3 and subject 5 experienced the extramely decrease. The research result showed that with deep breathing for the beginners diabetics sufferer could decrease the stres level, the stres scale score after the training were lower than stres scale score before ther training when the reading Al-Qur'an done continuously and intensively.

Keywords : reading Al-Qur'an, stres, diabetes mellitus

\section{ABSTRACT}

Penelitian ini bertujuan untuk mengetahui efektivitas pelatihan membaca Al-Qur'an secara tarti berdasarkan waqaf dan washal dengan pernapasan dalam untuk menurunkan stres pada penderita diabetes mellitus tipe dua. Penelitian ini menggunakan pendekatan quasi experimental dengan enam orang penderita diabetes mellitus. Pelatihan diberikan selama tiga minggu dengan materi diabetes mellitus, stres, membaca Al-Qur'an dengan pernapasan dalam yang dilaksanakan sebanyak lima kali pertemuan. Data skala stres yang terkumpul, dianalisis dengan visual inspection, yaitu tingkat stres subjek dibandingkan antara hasil pengukuran sebelum dan sesudah perlakuan dan terdapat perbedaan pada setiap subjek. Hasil penelitian menunjukkan bahwa pelatihan membaca Al-Qur'an secara tartil sesuai waqaf dan washal dengan pernapasan dalampada penderita diabetes mellitus tipe dua pemula dapat menurunkan tingkat stres. Hasil skor skala stres setelah pelatihan lebih rendah daripada skor skala stres sebelum pelatihan.

Kata kunci : Membaca Al-Qur'an, Stres, Diabetes Mellitus. 


\section{PENDAHULUAN}

Stres sudah diakui sebagai penyeba penyakit dan ketidaknyamanan individu. Stres dianggap sebagai penyebab meluasnya kasu penyakit, serta menjadi penyebab menurunnya daya tahan tubuh terhadap penyakit (Wilson, 2003)

Stres merupakan pengalaman emosi negatif yang disertai dengan perubahan fisiologis, kognitif, biokimia, dan perilaku, kemudian individu diarahkan untuk mengubah kejadian yang menimbulkan stres atau menyesuaika terhadap efek dari stres tersebut. Kejadian yan dianggap sebagai sumber stres (stressor) misalnya : suasana yang bising, kesesakan, hubungan dengan teman yang memburuk, dan suasan interviu pada pekerjaan baru (Taylor, 2003). Hal lain yang merupakan stresor adalah situasi krisis yaitu suatu keadaan yang menda-dak stres pada individu, misal-nya: in badai atau tsunami, gempa bumi; kejading be individu, yaitu kehilangan orang yang dicintal, kecelakaan, mendapat vonis penyakit tertent (Maramis, 2005 dan Sholeh, 2006)

Stres timbul karena adanya sesuatu yang hilang dari diri individu atau tidak tercapainya sesuatu keinginan. Apabila individu gagal memaknai kejadian dengan positif mak maki kejadian dengan positif, ona jack tres berlangsung lana karena proses koping yang gagal maka akan mengganggu jiwa da fisik individu (Mustamir, 2007).

Lebih lanjut, Mustamir (2007) menyatakan bahwa stres yang kronis atau terlalu lama dapa berbahaya dan memainkan peran yang penting dalam perkembangan banyak jenis penyakit. Gejala-gejala stres fisiologis seperti pernapasan yang dangkal, detak jantung yang semakin cepat, mulut kering badan berkeringat dan chaginya merume ba persian ena porsian uncer me melawan atau menghindar, fight or flight. Jik individu telah mengambil tindakan, yaitu melawan atau menghindar, maka dia akan memasuk keadaan relaksasi dan kembali ke keadaan homeostatis. Namun, ketika tanggapan fight or flight ini berlangsung terlalu lama, maka konsekuen-sinya akan mengganggu kesehatan.
Ketidak-seimbangan terus-menerus yang diciptakan oleh stres yang tak teredakan dapa menim-bulkan gejala fisik dan psikologis, seperti ketegangan otot, salah cerna, dan susa tidur yang lambat laun akan menimbulkan sakit.

Salah satu penyakit yang mempunyai fakto risiko stres adalah diabetes mellitus, yaitu suatu penyakit yang tubuh penderitanya tidak dapat otomatis mengendalikan kadar gula dalam darahnya, sehingga kadar gula dalam peredaran darah berlebihan. Kondisi ini terjad karena tubuh kekurangan hormon insulin yan diperlukan untuk mengubah gula menjad energi. Insulin adalah hormon yang dihasilkan oleh pankreas. Tubuh mengeluarkan energi untuk melakukan aktivitas. Energi berasal dar arbohidrat yang diubah menjadi glukosa, kemudian masuk ke dalam saluran darah dan menghasilkan energi. Glukosa merupakan sumber utama energi. Pada keadaan normal, insulin membantu glukosa dalam darah untuk memasuki sel-sel tubuh untuk diubah menjad energi. Bagi penderita diabetes, organ pankrea tidak dapat mengha-silkan hormon insulin sesuai dengan kebutuhan tubuh. Akibatnya, glukosa tidak dapat memasuki sel-sel tubuh, sehingga kadar gula dalam peredaran darah menjadi tinggi. Glukosa yang berlebihan ini . The idak menerima glukosa, walaupun kadarnya amat tinggi dalam darah. Ini menyebabk buh kekurangan energi (Mustamir, 2007).

Diabetes mellitus kini menjadi ancama yang serius bagi manusia dan telah menjadi penyebab kematian urutan ke tujuh di dunia. Prevalensi dan insiden penyakit ini meningkat secara drastis di negara-negara industri baru dan negara berkembang, termasuk Indonesia. i Asia, pre Di Asia, prevalens dice tes merkemen secara merata, bakk pasa penduduk kelas ekonomi menengah ke atas maupun penduduk yang tinggal di daerah kumuh (Sustrani, dkk 005 )

Berdasarkan dokumentasi Organisasi Keseatan Dunia (WHO) pada tahun 2003 terdapa 189 juta penduduk dunia yang mengidap diabetes mellitus. Sementara, di tingkat Asia terdap
89 juta lebih penderita, terutama di empa negara yaitu: India (32,7 juta penderita), RRC (22,6 juta penderita), Pakistan ( 8,8 juta penderita), dan Jepang (7,1 juta penderita) (Sustrani, dkk, 2005)

Jumlah penderita diabetes mellitus di Indonesia kini mencapai lima juta jiwa atau lima persen dari jumlah penduduk. Sekitar 2,5 1,3 persen dari 210 juta pendudu ju jiwa 1,3 persen dari 210 jut pendudu komplikasi diabetes mellitus. Jumlah penderit diabetes mellitus di Indonesia diperkiraka mengalami peningkatan dari 8,4 juta jiwa pada tahun 2000 menjadi sekitar 21,3 juta jiwa pada tahun 2030 mendatang. Tingginya angka tersebut menjadikan Indonesia peringkat keempat jumlah penderita diabetes mellitus terbanyak di dunia setelah Amerika Serikat, Has ini berdasarkan hasil surve thun 2003 dengan prevalensi diabetes mellitus di perkotaan mencapai 14,7 persen dan di pedesaan 7,2 persen (Sustrani, dkk, 2005) Jumlah penderita diabetes mellitus di Yogyakarta pada 2007 mencapai 1.835 oran atau sekitar 0,93 persen dari jumlah penduduk (http://dinkes.jogjaprov. go.id, 2010).

Penyakit diabetes mellitus yang banyak diderita (mencakup 90-95 persen) adalah diabetes tipe dua, yaitu karena tubuh tidak cukup menghasilkan insulin menurut kebutuhan tubuh atau mengounakan insulin untuk menurunkan glukosa di dalam darah (Lanywati, 2001). Langkah-langkah yang mest dilakukan penderita adalah penurunan ber badan bagi yang kelebihan berat, olahraga ata latihan fisik secara teratur, pengaturan pola makan yang baik, menghindari stres, da memeriksa kadar gula darah secara berkala.

Salmon (2000) menyatakan bahwa ketika mendapat vonis pertama kali mengidap diabetes mellitus, individu mengalami shock, karena merupakan vonis yang menakutkan, yang membuatnya diliputi bayang-bayang hidup tanpa harapan, yang terbesit dalan pikiran hanyalah kematian. Hal tersebut karen penyakit diabetes mellitus merupakan penyakit menahun dan seumur hidup. Diabetes mellitus juga merupakan suatu penyakit kronis dan sebagaimana lazimnya penyakit kronis, penya- kit ini sering menimbulkan perasaan tidak berdaya pada diri penderitanya. Perasaan in timbul karena berbagai macam sebab, antara lain: kondisi kesehatan penderita yang tidak menentu, yang diwarnai kesembuhan dan kekambuhan, serta kemungkinan terjadinya kemunduran fisik. Individu tidak dapa merima kenyatan serius ini. Prokop (1991) ment individu ketika in ala pedih, da rustrasi yang menyebabkan meningkatny gula darah. Salmon (2000) menambahka bahwa individu juga merasa bingung, berbua sesuatu tanpa berpikir jauh, dan tidak mampu menganalisis hal yang terjadi pada dirinya. Individu diliputi perasaan putus asa dan tidak berdaya. Vonis ini merupakan ancaman bagi kehidupannya dan tidak dapat mengembalikan dirinya pada kehilupan sebagainana sebeluma perua mengidap penyakit ini. pencen

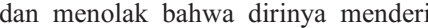
penyakit kronis yang mematikan (denial).

Potensi reaksi terhadap stres yang tinggi sangat bervariasi, ada individu yang cemas, takut, malu, marah, depresi, ataupun menolak (denial). Potensi respon perilakunya nampa terbatas, tergantung pada kondisi individu da kejadian yang menimpanya. Individu dapat juga mereaks dengan melawa stesor sat jer me tetapi secara fisiologis terjadi perubahan (Taylor, 2003).

Keadaan stres dapat mengacaukan hormonhormon dan menyebabkan buruknya kinerja organ-organ tubuh, sehingga berdampak pada rendahnya produksi dan sensitivitas insulin yang mengakibatkan tubuh tidak mampu mengubh gula darah menjadi energi, kemu-dian terjadi hiperglikemia yaitu tingginya kad he tres teralu lama dapat berahaya dan lama dapat berbahaya dan perkenkan peran yang penting di dalam perkentangan banyak jenis penyakit (komplikasi jantung, darah tinggi, gagal ginjal), sehingga perlu dilakukan upaya pengelolaa k menstabilkan tingkat stres pada 
hormon insulin tidak terganggu, sehingga tubuh mampu mengubah gula darah menjadi energ serta sintesis lemak (Mustamir, 2007).

Brooks dan Roxburgh (1999), Sharo (2000), dan Mustamir (2007) menyatakan reaksi terhadap stres terdiri dari beberapa aspek, yaitu:

a. Fisiologis, yaitu terganggunya pola-pola normal dari aktivitas fisiologis yang ada. Gejala yang timbul antara lain: sakit kepala, konstipasi, nyeri otot, turunnya nafsu seksual, dan cepat lelah.

b. Emosional, biasanya berupa keluhan sepert tegang, khawatir, cemas, marah, tertekan, dan rasa bersalah. Secara umum hal tersebut adalah sesuatu yang tidak menyenangkan.

c. Kognitif, yaitu tampak pada fungsi berpikir, konsentrasi, dan ingatan. Dalam kondis stres, fungsi berpikir akan terganggu karen dipengaruhi oleh kekhawatiran tentang konsekuensi yang terjadi.

Salmon (2000) menyatakan bahwa untuk menurunkan stres dapat dilakukan berbaga cara dan setiap cara dapat berubah setiap waktu. Khususnya dengan penyakit kronis atau yan mengancam kehidupan, diperlukan koping untuk mengurangi emotional distress yang mengiringi shock ketika diagnosis dijatuhkan. Salmon (2000) dan Taylor (2003) menyebutkan Saping mang (200) dat dilapat duap yang dap plakukan, yaitu koping yang memfokuskan pada problem (problem-focused coping), misalnya memberikan informasi yang berkaitan dengan penyakit ini, yaitu pelatiha cara mengetahui kadar gula darah da manajemen mengatasi diabetes, tetapi tidak selalu memadai. Yang ke dua adalah koping yang berfokus pada emosi (emotion-focused coping) atau juga disebut palliative, merupaka koping yang dipandang lebih efektif Hal in tergantung pada pengetahuan dan keahlian individu dalam melakukannya. Misalnya, pelatihan teknik relaksasi yang bermanfaa untuk menurunkan emosi negatif dan dorongan fisik individu.

Dalam penelitiannya tentang teknik koping yang efektif untuk menyesuaikan diri terhadap stres, Pargament, dkk.(1999) menyatakan bahwa partisipan penelitian yang menggunakan koping yang berfokus pada emosi (misalnya pernapasan diafragma dan relaksasi otot) lebi banyak mengalami penurunan distres daripada partisipan yang menggunakan koping yang berfokus pada penyelesaian masalah. Pargament, dkk (1999) juga menambahkan bahwa beberapa aktivitas religius yang dapat meringankan distres emosi antara lain: nonge-

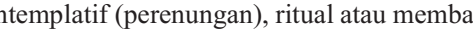
ca kitab suci. Aktivitas ini membawa individ pada ketenangan ketika menghadapi situas yang sulit.

Program manajemen stres terdiri dari tiga fase. Fase pertama, individu mempelajari ar stres dan cara mengidentifikasi stres. Fase ke dua, individu memperoleh dan mempraktekkan keterampilan koping stres. Fase ke tiga, yang diperoleh.

Beberapa program manajemen stres antara lain: mengidentifikasi stresor, memonitor stres, manajemen waktu, perilaku diet, membuat ujuan baru, dan membuat instruksi diri. Selai itu juga ada yang berhubungan secara fisik untuk menurunkan stres yaitu dengan pelatihan relaksasi, misalnya pelatihan relaksasi otot, meditasi transendental, yoga, dan hipnosis. Teknik ini dapat menurunkan detak jantung, ekanan darah, tekanan otot, serta kecemasen ,

Berdasarkan hasil penelitian Al-Qadi, di Florida, Amerika Serikat, menunjukkan bahwa hanya dengan mendengarkan bacaan $\mathrm{Al}$ Qur'an, individu (baik yang berbahasa Arab maupun yang bukan), mampu merasakan perubahan fisiologis yang besar, seperti penurunan depresi, bahkan dapat memperoleh ketenangan dan menolak berbagai macam enyakit (dalam peralata jantung, ketahanan otot, dan ketahanan kulit terhadap aliran listrik. Penemuan ini menunjukkan bahwa bacaan Al-Qur'an berpengaruh besar (hingga 97\%) dalam memberikan ketenangan dan penyembuhan penyakit.

Penelitian tersebut diperkuat oleh penelitian Muhammad Salim yang dipublikasikan ole
Universitas Boston, yang berjudul Ta'stir AlQur'an "Ala Wadzaif al-Jism al-Basyari w Qiyasuhu Biwashithah aj-hizah al-Muraqabah al-Iliktruniyah. Subjek penelitiannya terhadap lima orang sukarelawan yang terdiri dari tig pria dan dua wanita. Kelima orang tersebut sama sekali tidak mengerti bahasa Arab do mereka pun tida diperdengarkannya adal cipence tian initerbagi dua sesi, yaitu membaca-kan A Qur'an secara tartil, dan membacakan bahas Arab yang bukan dari Al-Qur'an. Kesimpulannya, responden mendapatkan kete-nangan sampai 65 persen ketika mendengarkan bacaa Al-Qur'an dan mendapatkan kete-nangan hanya 35 persen ketika mendengarkan bahas Arab yang bukan dari Al-Qur'an.

Berlandaskan penelitian tersebut, penulis ermater Al-Qur'an secara tartil pada penderita diabetes Al-Qun' an dialami akibat penola nna ketka merger penolakannya ketika mengetahui bahwa dirinya mengidap penyakit kron tersebut. Koping yang digunakan adalah gabungan antara koping yang berfokus pada emosi yaitu pernapasan diafragma dan latihan fokusperhatian, dengan membaca Al-Qur'an secara tartil. Pernapasan diafragma merupakan pengaturan pernapasan individu untuk menarik oksigen ke dalam paru-paru agar pola pernapasan individu menjadi rileks, latiha fokus-perhatian dengan membaca Al-Qur'an, yaitu dengan memberikan stimulus Al-Qur'an sebagai pengganti stimulus yang menimbulkan stres. Secara psikologis, membaca Al-Qur'an dapat menurunkan stres. Ketika stres, yang aktif adalah saraf simpatetik, secara fisiologis hati mendorong sekresi gula darah tetapi tubuh penderita diabetes mellitus tidak mampu menubah gula menjadi energi karene mendahnya produksi insulin yang dihasilkan pankreas, sehingga terjadi hiperglikemia (ting-giny kadar gula darah) kemudian membaca $\mathrm{Al}$ Qur'an secara tartil dengan pernapasan dalan yaitu mengaktifkan kerja saraf parasim-patetik dengan Al-Qur'an sebagai objek fokusperhatiannya untuk mengalihkan perhatian da stresor yang sebenarnya, sehingga tubuh kembali rileks, dan stres menurun. Pankreas juga dapat menghasilkan hormon insulin walaupun tidak optimal seperti individu yang tidak menderita diabetes mellitus, sehingga kadar gula darah turun dan tubuh dapat menghasilkan energi.

\section{METODE PENELITIAN}

Penelitan ini merupakan jenis eksperimental, yakni peneliti memberikan perlakukan (treatment) berupa pelatihan membaca $\mathrm{Al}$ Qur'an sebagai independen variabel (X) kepada subyek yakni penderita diabete mellitus tipe dua, selanjutnya mengamati da mencatat reaksi subyek, kemudian melihat hubungan antara perlakuan yang diberikan dan reaksi $($ perilaku $=$ variabel tergantung) yang muncul dari subyek yakni tingkat stres sebaga dependen variabel (Y). Hakekat tujua penelitian eksperimental alah meneliti pengaruh perlakuan terhadap perilaku yan imbul a perian

Sebagai bentuk kontrol dalam penelitian eksperimental, maka diperlukan variabe pendukung untuk dapat mengamati bahw perubahan variabel dependen yakni tingkat stress disebabkan karena adanya perlakuan dar variabel independen yakni pelatihan membaca Al-Qur'an. Adapun yang menjadi variabe pendukung dalam penelitian ini adalah kadar gula darah pada penderita diabetes mellitus tipe dua pemula yang menjadi subjek penelitian. Pengukuran kadar gula diukur dengan alat glucometer dan penentuan kategori kadar gula yakni di bawah $140 \mathrm{mg} / \mathrm{dl}$ merupakan kada glukosa normal bagi penderita dan di atas 200 $\mathrm{mg} / \mathrm{dl}$ merupakan kadar glukosa tinggi bagi penderita.

Penelitian eksperimental membutuhkan sebuah rancangan atau desain untuk menentukan langkah dalam pemberian perlakuan yang diinginkan dan melihat pasilnya (Kerlinger, 2003). Penelitian in menggunakan quasi experimental design dengan model pretest-posttest single case subject, yaitu sejumlah subjek yang dipilih diberikan pretest dan posttest untuk melakukan kontro onstansi terhadap proactive history.

Analisa data dilakukan dengan membandingkan hasil individual pada skor tingka 
stress subjek secara visual inspection. Tingkat tress dibandingkan antara hasil pengukura sebelum dan sesudah perlakuan diberikan.

Penelitian ini dilakukan pada enam penderita diabetes mellitus tipe dua pemul Daerah Pemerintah Kota Yogyakarta (RSUD Wirosaban), yang memenuhi kriteria sebagai crikut; beragama Qur'an secara tartil, dan meniliki usia $35-50$ tahun (berdasarkan prosentase tertinggi penderita diabetes mellitus pemula), memilik tingkat ekonomi menengah, menderit penyakit diabetes mellitus maksimal dua tahun, memiliki skor sedang sampai dengan tingg pada skala stres, tidak mengkonsumsi obat dan bersedia mengikuti penelitihan. Kriteria tersebut dimaksudkan agar perubahon variabel dependen disebabkan karena adanya perlakuan dari variabel independen.

Pada penelitian ini variabel tingkat stres diukur menggunakan skala stres, dengan penyusunan skala yang dikonstruksikan sendir oleh peneliti. Penyusunan skala stres berdasarkan tiga aspek stres pada individu yakni aspek fisiologis, emosional dan kognitif menurut Brooks dan Roxburgh (1999).

Skala stres ini berupa serangkaian pernyataan tertulis yang secara logis berhubungan dengan masalah penelitian. Setiap pernyataan tersebut digunakan untuk memperoleh informasi mengenai subyek yang mempunyai makna dalam penyajian hipotesa (Nazir, 1999).

Skala stress dikembangkan dengan mode skala Likert yang sudah dimodifikasi dengan menghilangkan jawaban ragu-ragu dengan pertimbangan agar subjek tidak memberikan jawaban yang mengumpul di tengah (Hadi, 2000). Masing- masing indikator terdiri dari item favourable dan item unfavorable serta menyediakan empat altem un jawabar menyediakan enpat altenatif jawaban yan Tidir dari Sangat Sesuai (SS), Sesuai (S), Tidak Sesuai (TS), Sangat Tidak Sesuai (STS) Pemberian skor pada skala ini bergerak dari sampai 1 untuk item yang mendukung (favourable), sedangkan untuk skor item yang tidak mendukung (unfavourable) bergerak dari 1 sampai 4 .

Skala stres juga dilakukan uji coba pada 16 subjek di Rumah Sakit PKU Muhammadiyah Yogyakarta dan 15 subjek di Rumah Sakit Umum Daerah Pemerintah Kota Yogyakarta sebagai langkah dalam uji kelayakan suatu instrumen penelitian. Pengujian validitas yang dilakukan adalah dengan menggunakan validitas isi yang diestimasi lewat pengujian res is yang diestim

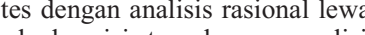
gan analisi rasional atau professional judgment (Azwar, 2009). Hasil analisis rasional terhadap isi te dilakukan oleh orang ahli dan disetujui untuk dilakukan uji coba kepada sampel lain yang representatif dengan sampel penelitian serta diuji secara statistik.

Skala stres yang dihasilkan adalah 0,872 dan diperoleh 21 item yang tidak reliabel dari 50 item. Skala pengukuran yang reliabel sebaiknya memiliki nilai Alpha Cronbach minimal 0,70 . Koefisien reliabilitas skala stres setelah meniadakan item-item yang tidak reliabel berubah menjadi 0,929 , sehingg menjadi 29 item yang reliabel tersebar pada seluruh aspek

Persiapan penelitian dilakukan dengan terlebih dahulu menyusun modul pelatihan yang dikonstruksikan sendiri oleh peneliti. Selanjutnya persiapan terapis untuk melakukan terapi yang dilaksanakan oleh psikolog da Dinas Keschatan Kabunten Sleman dan kodan kocraprean untuk menjaga objektivitas penelitian. Modul yang sudah tersusun, dilakukan uji coba modul di RS PKU Yogyakarta yang diikuti tuju peserta yang merupakan pasien diabete mellitus dengan kriteria yang sesuai dengan subjek penelitian. Modul yang sudah diuj cobakan, dapat digunakan sebagai bahan dalam pelaksanaan penelitian pada subjek yang sebenarnya.

Penelitian dilakukan dengan melakukan pengukuran awal (pretest) pada subjek penelitian mengenai tingkat stres yang menggunakan skala stres. Setelah pemberia skala stres, subjek menjalankan prose pelatihan yang berlangsung selama lima kal pertemuan. Setiap pertemuan dilakukan selam 100 menit dengan waktu selama tiga minggu.

Perlakuan diberikan melalui tiga tahap yakni tahap pengenalan yang dilakukan pada pertemuan pertama dengan memberika pengarahan, informed concent, skala stress pada langkah pretest, tes kadar gula darah, dan pengisian harapan-harapan dalam pelaksanaan pelatihan. Tahap kedua adalah tahap pelatiha yang berlangsung dalam tiga sesi yakni pada pertenuan keda perap yang menggunakan metode brain storming, materi stres berupa penyebab dan pengaru stres terhadap kesehatan. Pertemuan ketig mereview kembali hasil pada pertemuan sebelumnya dan diberikan materi managemen stres serta latihan pernapasan dalam ole terapis, dilanjutkan dengan pemberian pelatihan oleh ko-terapis mengenai baca $\mathrm{Al}$ Qur'an untuk surat pendek. Hal ini dilakuk Qu 'a cempat ko-terapis mengevalusi keempat, ko-terapis mengevaluasi kemba hasil dari pertenuan sebelumnya dan memberikan pelatihan membaca Al-Qur'a untuk surat panjang sesuai dengan modul pelatihan. Tahap terakhir pada pertemua kelima adalah sesi penutup dengan mengevaluasi kembali hasil pertemuan sebelumnya dan mengulang baca Al-Qur'an untuk surat panjang sesuai modul. Setelah itu diberikan pengukuran skala stress sebagai langka posttest dan dilanjutkan dengan pengetesan kadar gula darah.

\section{HASIL PENELITIAN DAN}

PEMBAHASAN

Berdasarkan pengukuran tingkat stres subjek sebelum dan sesudah perlakuan, maka dapat disimpulkan bahwa terdapat perbedaan tingkat stres pada subjek sebelum mendapatkan perlakuan dengan sesudah mendapatkan perlakuan relaksasi dengan membaca Qur' Qurean 1 dan subjek 4 menum hanya sedik. Subjek 1 dan subjek 4 menum 3 hana sedikit atau dapat pula disebut tidak mengalam penurunan yang berarti, Subjek 2 dan subjek mengalami penurunan skor skala stres tida banyak dan penurunan itu tidak mengubah posisi kategori subjek pada kategori stres sedang, yaitu berada diantara skor 58 sampa 87. Subjek 3 dan subjek 5 mengalam penurunan yang berarti, dimana penurunan yang tajam pada subjek 3 hingga 37 poin, sedangkan pada subjek 5 mengalami penuruna 22 poin.

\section{KESIMPULAN}

Adanya penurunan yang tajam untuk tingkat stres pada kedua subjek menunjukkan bahwa pelatihan membaca Al-Qur'an yang diberikan ebagai latihan untuk self help dapat menurunkan stres jika dilakukan secara terusmenerus dan intensif hingga pertemua terakhir. Fakta ini membuktikan bahwa hipotesis penelitian yakni pelatihan membaca Al-Qur'an secara tartil dapat menurunkan tingkat stres pada penderita diabetes mellitus tipe dua pemula telah terbukti, dengan syara melakukan tugas di rumah secara terusmenerus.

Hasil penelitian di atas menunjukkan bahwa pelatihan membaca Al-Qur'an secara tartil sesuai dengan waqaf dan washal sesuai dengan tujuannya, yakni dapat menurunkan stres subjek sehingga menjadi rileks. Selain itu , jug sebagai self help, subjek dilatih membaca AlQur'an untuk mengendalikan ketegangan yang dirasakan dapat memicu meningkatnya kadar gula darah. Setelah metode ini diberikan sebagai terapi kemudian subjek dapa mengembangkan keterampilannya selam tau perlakuan sehingo subjek in keterampilan tersebut ke dalam kehidupan sehari-hari untuk mengontrol stres dalam kehidupannya (Utami, 1993 dan Billing, 2000). Pelatihan membaca Al-Qur'an secara tartil sesuai dengan waqaf dan washal dengan pernapasan dalam, bila dilakukan secara intensif, sesuai dengan hasil penelitian in adalah dapat menurunkan stres. Mustamir (2007) menyatakan bahwa pernapasan yang epat merupakan penawar stres, sehingg berakibat positif terhadap kesehatan fisik ecara menyeluruh.

Lloyd, dkk (2005) menyatakan bahwa tingkat stres bagi penderita diabetes berhubungan erat dengan kadar gula darah. Apabila tingkat stres penderita diabetes mellitus tingg dapat dipastikan pula bahwa kadar gula dalam 
darah penderita juga tinggi. Pengalaman yang sering memicu stres berat mempengaruh kontrol diabetes, yaitu pada tingginya kada gula darah yang dapat mengakibatkan komplikasi diabetes seperti jantung, gagal ginjal dan saraf.

Ramadhani (2007) menyatakan bahwa membaca Al-Qur'an secara tartil sesuai dengan waqaf dan washal adalah membaca Al-Qur'an secara tartil dengan pengaturan napas sesua waqaf dan washal. Waqaf berarti tempa berhenti, yaitu ketika membaca Al-Qur'a individu tidak boleh menghentikan bacaan pad kata yang dapat merusak pengertian karen tidak ada waqaf. Ketika membaca Al-Qur'an kemudian menemui tanda waqaf berarti berhenti, memutus suara di akhir kalimat serta mengambil napas untuk beristirahat. Washa berarti meneruskan yakni membaca terus tidak berhenti serta menyempurnakan semua bacaan dan tanda baca dengan tanpa mengambil napa di tengah-tengah membaca. Waqaf dan washal sangat penting dilakukan untuk menghinda rusaknya makna yang terkandung di dalan ayat-ayat Al-Qur'an.

Aturan tanda Waqaf dan washal melatih individu melatih pernapasan ketika membaca Al-Qur'an. Hal ini dikarenakan wakt membaca individu dapat menentukan kapan boleh mengambil napas dan menentukan wakt untuk tidak boleh mengambil napas. Individ (1) lengan wact dan Jen teratur dan lebih panjang, karena dalam ayatayat tertentu individu dituntut untuk mengambil napas dalam-dalam, karen panjangnya ayat harus dibaca tanpa boleh berhenti untuk mengambil napas, dan setelah itu dengan membaca ayat tersebut individu menghembuskan napas sampai habis.

Relaksasi pernapasan dalam adalah individu mengambil napas dalam dengan pola yang pelan. Setiap tarikan napas, individ menggunakan otot diagfragma untuk menghirup oksigen yang dalam sampai ke paruparu. Stres atau dorongan otonom, individ lebih sering bernapas dangkal, cepat, mak pernapasan diafragma menurunkan stre dengan mengganti pola pernapasan yang lebih rileks.

Pernapasan ini dapat dipraktikan dengan cara beridiri atau duduk atau berbaring denga posisi yang nyaman, mata tertutup, dan mengambil napas pelan-pelan selama 3-5detik sampai paru-paru penuh terisi udara. Otot diafragma mengembangkan perut karena udar dihirup. Individu diminta untuk merasakan selama dua detik kemudian individu meng menghembuskan napas pelan-pelan 3-5 detik melalui hidung dan individu diminta untuk merasakan sensasi perut melemas. Pernapasan ini lebih baik bila dilakukan melalui hidung. Individu hendaknya memfokuskan pada sensasi dalam pernapasan, misalnya merasakan mengembang dan mengempisnya paru-paru, merasakan keluar masuknya udara, dan tidak berfikir tentang stres yang dialalminya (Miltenberger, 2003)

Relaksasi dengan metode pernapasan yang demikian memiliki persamaan dengan pernapasan ketika membaca Al-Qur'an secara tartil sesuai dengan waqaf dan washal, yakn dapat mengaktifkan saraf parasimpatik. Hanya saja, perbedaannya terletak pada perhatian yang tertuju pada pengambilan dan penghembusan napas serta bacaan Al-Qur'an.

Utami (1993) menyatakan bahwa dalam relaksasi, otak mengirim perintah untuk mengurangi aktivitas sistem saraf simpatetik dan meningkatkan aktivitas sistem saraf parasimpatetik dan selanjutnya mencurahkan asektilkolin yang beraksi pada organ-orga tubuh dan akan mengantarkan individu pada keadaan istirahat dan rileks. Ketika individu mengalami stres maka akan ada ketegangan pada otak dan otot sehingga dengan mengaktifkan saraf parasimpatetik deng pengan te mividu mudah masuk dalan kondisi rileks.

Mustamir (2007) menyatakan bahwa pernapasan yang tepat merupakan penawa stres, sehingga berakibat positif terhadap kesehatan fisik secara menyeluruh. Bila individu terbiasa bernapas pendek, maka kantong paru-paru sulit dikembangkan.
Kemampuan paru-paru untuk menghisap da menghembuskan udara secara minimu tergantung pada besar kecilnya tubuh dan gerakan rongga dada dari individu. Pernapasan yang pendek dan sedikit harus diubah menjadi pernapasan panjang dan banyak untuk meningkatkan kesehatan fisik dan mental.

Berdasarkan hasil penelitian yang telah dilakukan, maka saran yang dapat diberikan adalah sebagai berikut:

\section{Bagi Subjek penelitian}

Diharapkan dapat mempraktikkan kembali teknik relaksasi yang telah diperoleh secar intensif dan dapat menyeimbangkan kondis psikologis yang dapat memicu stres.

\section{Bagi Peneliti Selanjutnya}

Peneliti selanjutnya yang ingin melakukan replikasi terhadap penelitian ini, disarankan untuk mempertimbangkan menganai karakteristik subjek, situasi saat terapi bag subjek di rumah, dan permasalahan yang dialami subjek.

\section{DAFTAR PUSTAKA}

Alsa, A. 2004. Pendekatan Kuantitatif dan Kualitatif serta Kombinasinya dalan Penelitian Psikologi: Satu Uraian Singka dan Contoh Berbagai Tipe Penelitian. Yogyakarta: Pustaka Pelajar.

Azwar, Saifuddin. 2009. Metode Penelitian Yogyakarta: Pustaka Pelajar.

Billing, D.W., Folkman, S., Acree, M., \& Moskowitz, J.T. 2000. Coping and Physical Health during Caregiving: The Roles of Positive and Negative Affect. Journal of Personality and Social Psychology, 791, 131-142

Brooks, R.J. and Roxburgh, S. 1999. Gender Differences in the Effecdt of the Subjective Experience of Diabetes and Sense of Control on Distress. Health, 399-409

Hadi, Sutrisno. 2000. Metodologi Research. Jilid 1. Yogyakarta: Andi Offset.

Dinkes Yogyakarta. 2010. . Dinas Kesehatan Yogyakarta.

Kerlinger, F.N. 2003. Asas-Asas Penelitian
Behavioral, Edisi Revisi. Yogyakarta: Gadjah Mada University Press.

Lanywati, E. 2001. Diabetes Mellitus Penyakit Kencing Manis. Yogyakarta: Penerbit Kanisius

Llyod, C., Smith, J., dan Weinger, K. 2005. Stress and Diabetes: A Review of the Links. Diabetes Spectrum, 18, 2, 121-127

Maramis, W.F. 2005. Catatan Ilmu Kedokteran Jiwa. Surabaya: Airlangga University Press.

Miltenberger, R.G. 2003. Behavior Modification Principles and Prosedures. Third Edition. United State of America: Thomson Wadsworth.

Mustamir, 2007. Sembuh dan Sehat dengan Mukjizat Al-Qur'an. Yogyakarta: Lingkaran 2007. Rahasia Energi Ibadah untuk Penyembuhan. Yogyakarta: Lingkaran

Nazir, M. 1999. Metode Penelitian. Jakarta: Ghalia Indonesia.

Pargement, K.I. dan Cole, B. 1999. The Vigil Religion and the Search for Control in th Hospital. Journal of Health Psychology, 4, 3 327-341. London: Sage Publication

Prokop, C.K., Bradley, L.A., Burish, T.G., Anderson, K.O., \& Fox, J.E. 1991. Healt Psychology Clinical Methods and Research. New York: Macmillan Publishing Company.

Ramadhani, E.Z. 2007. Super Health Gava Hidup Sehat Rasulullah. Yogyakarta: Pro-U Media.

Salmon, P. 2000. Psychology of Medicine and Surgery. New York: John Wiley \& Sons, Inc Sustrani. 2005. Diabetes. Jakarta: Gramedia Pustaka Utama

Utami, M.S. 1993. Prosedur Relaksasi. Yogyakarta: Fakultas Psikologi Universitas Gadjah mada

Wilson, P. 2003. Meditasi Tanpa Mistik Translation Copyright. Jakarta: Penerbit Erlangga 